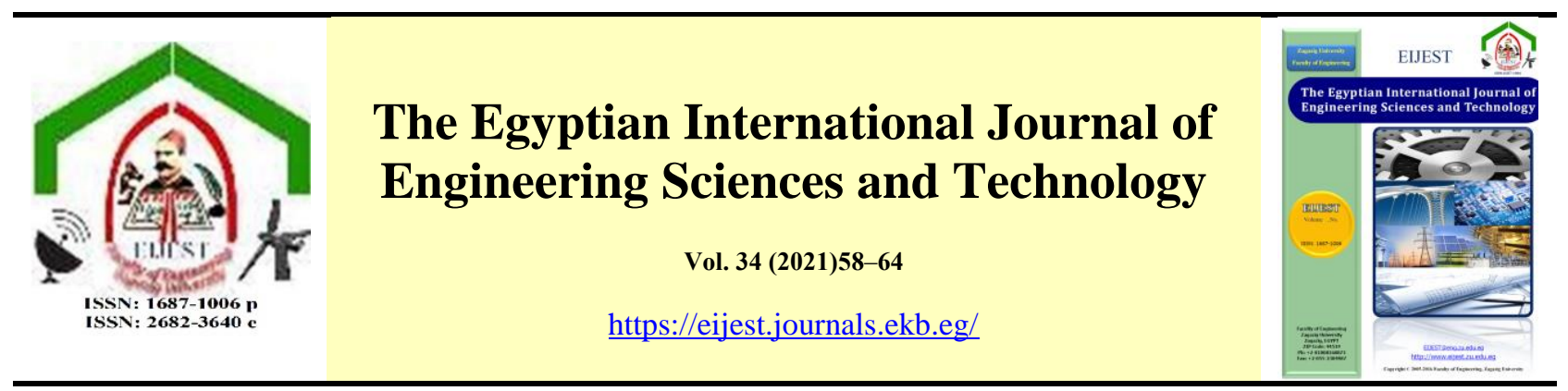

\title{
Improved mechanical properties of natural-synthetic hybrid composites
}

\author{
Marwa A. Abd El-baky ${ }^{*}$, Mona Megahed, Hend H. El-saqqa, Amal E. Alshorbagy
}

Mechanical Design and Production Engineering Department, Zagazig University, Zagazig 44519, Egypt

\begin{tabular}{l}
\hline A R T I C L E I N F O \\
\hline Keywords: \\
Hybrid composites \\
Mechanical properties \\
Sugarcane bagasse and glass \\
fiber \\
Impact \\
Hardness
\end{tabular}
\begin{abstract}
A B S T R A C T
This study is an attempt to utilize sugarcane bagasse (natural fiber) with glass fiber (synthetic fiber) to fabricate new types of hybrid composites. To explore the best mechanical properties, six composites with different layering sequence and different fibers amounts were fabricated via hand lay-up method. The tensile, impact, flexural and hardness properties were compared. Scanning electron microscopy was used to adapt to analyze the hybrid natural composite specimens' damage. Results revealed that the tensile, impact, flexural and hardness properties of sugarcane bagasse/polyester composites can be enhanced by its hybridization with glass fiber reinforcement. Different Layering configurations and the relative fiber amounts have noticeable impacts on the mechanical properties. Ultimate tensile strength and strain to failure of $\left[\mathrm{G} / \mathrm{SCB} / \mathrm{G}_{4} / \mathrm{SCB} / \mathrm{G}\right]$ are about 1.10 and 1.24 times those of $\left[\mathrm{G}_{2} / \mathrm{SCB} / \mathrm{G}_{2} / \mathrm{SCB} / \mathrm{G}_{2}\right]$. Flexural strength and flexural strain of [G3/SCB2/G3] are about 1.88 and 1.63 times those of [G2/SCB/G2/SCB/G2]. Moreover, flexural strength and flexural strain of [G3/SCB2/G3] are about 2.19 and 1.13 times those of $[\mathrm{G} / \mathrm{SCB} / \mathrm{G} 4 / \mathrm{SCB} / \mathrm{G}]$. Edgewise impact strength of [G3/SCB2/G3] is about 1.08 and 1.17 that of $[\mathrm{G} 2 / \mathrm{SCB} / \mathrm{G} 2 / \mathrm{SCB} / \mathrm{G} 2]$ and $[\mathrm{G} / \mathrm{SCB} / \mathrm{G} 4 / \mathrm{SCB} / \mathrm{G}]$. Flatwise impact strength of $[\mathrm{G} 3 / \mathrm{SCB} 2 / \mathrm{G} 3]$ is about 1.06 and 1.10 that of $[\mathrm{G} 2 / \mathrm{SCB} / \mathrm{G} 2 / \mathrm{SCB} / \mathrm{G} 2]$ and $[\mathrm{G} / \mathrm{SCB} / \mathrm{G} 4 / \mathrm{SCB} / \mathrm{G}]$. Hardness values of $[\mathrm{G} 3 / \mathrm{SCB} 2 / \mathrm{G} 3],[\mathrm{G} 2 / \mathrm{SCB} / \mathrm{G} 2 / \mathrm{SCB} / \mathrm{G} 2]$ and $[\mathrm{G} / \mathrm{SCB} / \mathrm{G} 4 / \mathrm{SCB} / \mathrm{G}]$ are, respectively, $1.11,1.03,0.98$ that of $[\mathrm{G} 2 / \mathrm{SCB} 4 / \mathrm{G} 2]$. The advantages of the hybridization of reinforcements in this work are the low price besides the light weight with comparable mechanical properties. Consequently, the recommended hybrid composites can be utilized in moderate load applications. Moreover, the suitable selection of the amounts of fibers and stacking sequence produces fabricated hybrid composites attaining property profiles which are close to glass fiber/polyester composites in terms of specific properties.
\end{abstract}

\section{INTRODUCTION}

Lately, natural fibers are broadly utilized as reinforcing constituents in polymeric matrix composites owing to their light weight, biodegradability, low price, and recyclability [1-3]. Numerous kinds of natural reinforcement are considered to be available as sisal, rice straw, jute, and cotton [4,5]. However, the main problems concerned utilizing these natural fibers as a reinforcement are the high moisture uptake, the poor wettability and also, the environmental degradation. To use natural fibres lonely in polymeric matrix composite is inadequate. Hybridization can be

* Corresponding author. Tel: +201273831106, +201095613501.

E-mail address: dr.marwa2013@yahoo.com . 
attained by adding synthetic fibres as glass fiber $(\mathrm{G})$ or carbon reinforcement to natural fibres. Hybrid polymeric composites are produced to keep the merits of both fibre reinforcement constituents. As a result, a balance in the mechanical behavior and proper price will be achieved [6].

Sugarcane bagasse (SCB) is considered as a one of the promising reinforcing materials $[7,8,9]$. SCB can be utilized as a reinforcement in polymer composites due to its abundant availability, low density, low pre-treatment costs and acceptable mechanical properties. It also satisfies the greening requirements by being biodegradable, recyclable and reusable [8-10]. SCB reinforced composites can be used in applications such as furniture, interior panels, wall lining, doors, toys, building and construction industry (panels, false ceilings, partition boards etc.) packaging, automobile and railway coach interiors and storage devices with the advantage of lower cost and good quality $[11,13]$.

Diverse studies have been carried out to understand the structure, mechanical properties, and the effect of chemical modification on SCB and its usage in reinforcing composite materials [14-16]. Literature review demonstrates the influence of the hybridization process of reinforcement on the mechanical performance of SCB reinforced polymeric composites. It was reported by Saw et al. [17] that SCB /coir composite exhibits the highest flexural strength, however, SCB /coir/SCB composite exhibits the highest tensile strength and modulus. Later, the same authors [18] proved that, the addition of jute to SCB improves the tensile properties and decreases the moisture uptake of the fabricated hybrid composite. The existence of jute fibre at the composite external layers enhances the tensile properties.

Tewari et al. [19] studied the effect of adding SCB with different weight fractions $(15,20,25$ and 30 wt. \%) on the mechanical properties of sugar cane/G fibers reinforced polymeric composites. The results revealed that the optimum tensile strength, Young's modulus, and the flexural strength were reported for hybrid polymeric composites filled with 15 wt. \% sugar cane bagasse reinforcement but the optimum elongation was recorded for hybrid one filled with 30 wt \% sugar cane bagasse reinforcement. Otto et al. [20] studied the physical and mechanical properties of ployurethan (PU) reinforced with $\mathrm{SCB}$, rice husk, or sisal fibers hybrid polymeric composites. The hybrid polymeric composite based on $82 \%$ rice husk and $18 \%$ SCB increases all the physical and mechanical properties of ployurethan. As reported by Attia et al. [21], the mechanical performance of hybrid composites are influenced by different parameters as the fibers amounts, fibers configuration, type and layering sequence.

The main objective of this article is to investigate the impact of essential parameters, namely fibers amounts and stacking sequence on the mechanical performance of SCB/G hybrid polymeric composites. Sugar cane bagasse reinforcement was chemically treated with sodium hydroxide $(\mathrm{NaOH})$ to make $\mathrm{SCB}$ more compatible with polyester matrix and thus the mechanical performance of the fabricated composites will be increased. To obtain the optimum mechanical properties, 6 different hybrid composites with different fibers amounts and stacking sequence were manufactured. Their tensile, impact, flexural and hardness properties were compared. In all previous studies, SCB was used in the chopped form. This form has no regular distribution in each ply. In this study, SCB sheets was initially produced and utilized as a reinforcement mat to ensure the regular distribution of SCB in each ply.

\section{MATERIALS AND METHODS}

\subsection{Materials}

E-glass fiber mat and sugarcane bagasse were used as synthetic and natural reinforcements, Fig. 1. The mechanical properties of glass fiber and sugar cane bagasse reinforcement are shown in Table 1 . Unsaturated polyester was selected as a polymeric matrix. The mechanical properties of polyester resin are presented in Table 2.
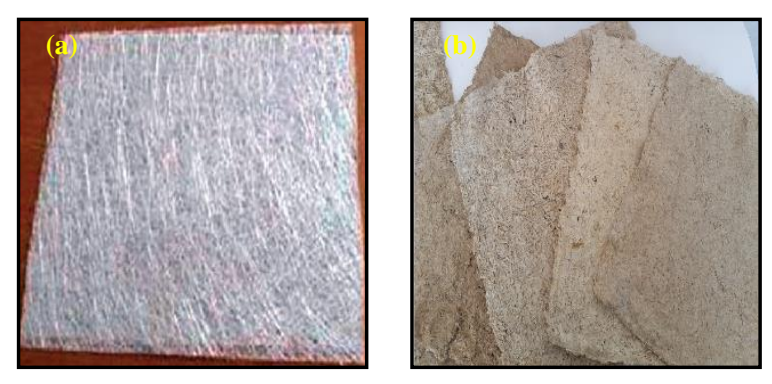

Fig.1. (a) E-glass mat and (b) sugarcane bagasse.

\subsection{Chemical treatment using sodium hydroxide}

Soft inner pulp of sugar cane bagasse reinforcement was washed with running water to get rid of any excess sugar and dirty particles. SCB were 
sundried for four weeks before chopping into small

fibers of $30 \mathrm{~mm}$ in length. Afterwards, SCB was immersed in 5 wt. \% NaOH solution for 48 hours. Hence, fibrillation ocuured thus improving fibre/polyester interfacial adhesion and enhanced mechanical properties can be attained [24].

Table 1. Properties of sugarcane bagasse and glass fabrics [22].

\begin{tabular}{|c|c|c|}
\hline Property & E-glass fiber & $\begin{array}{c}\text { Sugarcane } \\
\text { bagasse }\end{array}$ \\
\hline Average diameter, $\mu \mathrm{m}$ & 13 & 279 \\
${\text { Areal density, } \mathrm{g} / \mathrm{m}^{2}}^{3}$ & 300 & 300 \\
Density, g/cm $^{3}$ & 2.5 & $1.1-1.6$ \\
Young's modulus, GPa $^{2}$ & 76 & $5.1-6.2$ \\
Elongation, \% & $1.8-3.2$ & $6.3-7.9$ \\
Tensile strength, MPa & $2000-3500$ & $170-350$ \\
\hline
\end{tabular}

Table 2. Properties of polyester resin [23].

\begin{tabular}{|c|c|}
\hline Property & Polyester \\
\hline Apperance & Yellow liquid \\
& \\
Proportion of accelerator, cobalt & $1.0-1.5 \%$ of resin \\
naphthenate & vol. \\
Density, $/ \mathrm{cm}^{3}$ & 1.09 \\
Elongation, $\%$ & 3.0 \\
Tensile modulus, GPa & 3.1 \\
Tensile strength, MPa & 65 \\
Flexural strength, MPa & 100 \\
Flexural modulus, GPa & 3.5 \\
\hline
\end{tabular}

This blend was boiled for two hrs until sugar cane bagasse reinforcement became soft. Sugar cane bagasse reinforcement was cleaned and crushed with a mallet. The crushed sugar cane bagasse reinforcement was regular distributed in a mold $\left(40 \times 40 \mathrm{~cm}^{2}\right)$ then was left in air for 24 hrs to get dry. SCB mat was separated from the mold then dried in a hot oven to remove the moisture.

\subsection{Fabrication of composite laminates}

Hand lay-up method used to fabricate six SCB/G/polyester composites presented in Table 3 can be summarized as follows:

Polyester resin and catalyst were mixed and manually stirred, using a stir rod, for 5 minutes. The blend was applied to the reinforcement utilizing a brush and a metallic roller. Afterwards, the mold was compacted at a pressure of 1.2 bar. The constructed laminates were completely cured at ambient temperature after seven days. Then, the hybrid composite samples were cut into the requested dimensions corresponding to the test standards.
Table 3. Details of the fabricated SCB-G/polyester composites.

\begin{tabular}{|c|c|c|c|c|}
\hline \multirow{2}{*}{ Composite } & \multicolumn{2}{|c|}{$\begin{array}{c}\text { Fiber volume } \\
\text { fraction, \% }\end{array}$} & \multicolumn{2}{c|}{$\begin{array}{c}\text { Relative fabric volume } \\
\text { fraction, \% }\end{array}$} \\
\cline { 2 - 5 } & $\mathrm{G}$ & $\mathrm{SCB}$ & $\mathrm{G}$ & $\mathrm{SCB}$ \\
\hline$\left[\mathrm{G}_{2} / \mathrm{SCB}_{4} / \mathrm{G}_{2}\right]$ & 3.82 & 8.68 & 30.56 & 69.44 \\
{$\left[\mathrm{G}_{8}\right.$} & 15.89 & 0.0 & 100 & 0.0 \\
{$\left[\mathrm{G}_{3} / \mathrm{SCB}_{2} / \mathrm{G}_{3}\right]$} & 7.96 & 6.03 & 56.9 & 43.1 \\
{$[\mathrm{SCB}]_{8}$} & 0.0 & 11.64 & 0.0 & 100 \\
{$\left[\mathrm{G}_{2} / \mathrm{SCB} / \mathrm{G}_{2} / \mathrm{SCB} / \mathrm{G}_{2}\right]$} & 7.55 & 5.72 & 56.9 & 43.1 \\
{$\left[\mathrm{G} / \mathrm{SCB} / \mathrm{G}_{4} / \mathrm{SCB} / \mathrm{G}\right]$} & 7.94 & 6.01 & 56.9 & 43.1 \\
\hline
\end{tabular}

\subsection{Measurement and characterization}

\subsubsection{Fiber volume fraction}

The relative and overall fiber volume fractions were determined as follows, [25]:

$$
\begin{aligned}
\mathrm{v}_{f, i} & =\frac{m_{f i} n_{f i}}{\rho_{f i} h} \\
V_{f} & =\sum_{i=1}^{N_{f}} \mathrm{v}_{f_{i}}
\end{aligned}
$$

where, $m_{f i}, \rho_{f i}, n_{f i}$, and $\mathrm{v}_{f, i}$ are, respectively, the areal density, volumetric density, number of plies, and volume fraction of fiber " $i$ ". $V_{f}$ denotes the total fiber volume fraction. $h$ is the measured thickness of the laminate. $N_{f}$ refers to the number of the used fabrics, i.e. sugarcane bagasse (SCB) and glass (G).

\subsubsection{Density}

The density of the fabricated hybrid natural composites were determined using Archimedes (buoyancy) method according to [26]. Soybean oil with density of 0.907 provided from Sigma Aldrich was utilized.

\subsubsection{Mechanical testing}

Tensile and flexural tests were conducted on Jinan Testing Machine WDW $100 \mathrm{kN}$ according to [27,28]. Impact tests were conducted on Izod impact testing machine (type Avery Denison) according to [29]. Hardness was measured using PCE-1000N Hardness Tester Instrument according to [30].

\subsubsection{Specific properties}

Specific property is the experimental quantity was divided by the composite density. Specific properties concept can be utilized when comparing different composite materials. 


\subsubsection{Scanning electron microscopy (SEM)}

Morphological analysis was conducted to investigate the failure of the polymeric composite coupons. The failed surface was coated with gold and kept in an ionizer. Images were taken by subjecting the failed surface to $20 \mathrm{kV}$.

\section{RESULTS AND DISCUSSIONS}

\subsection{Tensile properties}

It is clear from Figs. 2 and 3 that $[\mathrm{SCB}]_{8}$ exhibits the lowest ultimate tensile strength and strain to failure. Whilst, $[\mathrm{G}]_{8}$ has the highest ones.

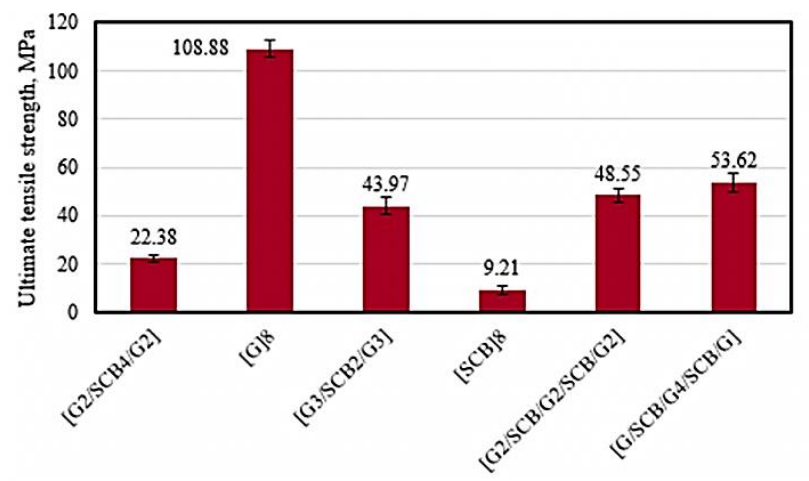

Fig. 2. Ultimate tensile strength of natural hybrid composites.

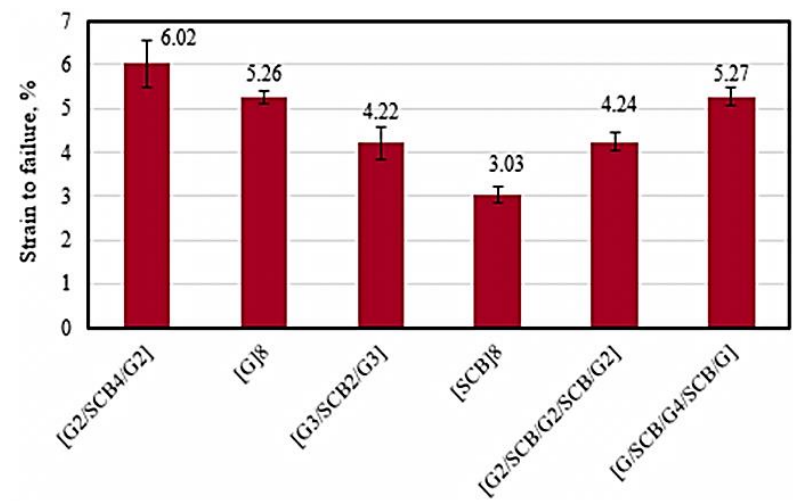

Fig. 3. Strain to failure $\%$ of natural hybrid composites.

For hybrid composites, the tensile strength and strain to failure of $\left[\mathrm{G}_{2} / \mathrm{SCB}_{4} / \mathrm{G}_{2}\right]$ are about 2.43 and 1.99 times those of $[\mathrm{SCB}]_{8}$. Which means that hybridizing SCB reinforced composite with G-fiber improves the tensile properties. The tensile strength and strain to failure of $\left[\mathrm{G}_{3} / \mathrm{SCB}_{2} / \mathrm{G}_{3}\right]$ are, respectively, 4.77 and 1.39 times those of $[\mathrm{SCB}]_{8}$. It was observed that as G-fiber weight content increases, the tensile behaviour are enhanced.

Stacking sequence slightly affects the tensile performance of natural hybrid composites. The ultimate tensile strength and strain to failure of $[\mathrm{G} / \mathrm{SCB} / \mathrm{G} 4 / \mathrm{SCB} / \mathrm{G}]$ are about 1.10 and 1.24 times those of $\left[\mathrm{G}_{2} / \mathrm{SCB} / \mathrm{G}_{2} / \mathrm{SCB} / \mathrm{G}_{2}\right]$. This is owing to the good load transfer that obtained from the weak skin plies, thus improving the crack growth by the strong inner plies. This is consistent with that recorded by Selmy et al. [31] for unidirectional glass/random glass hybrid composites.

\subsection{Flexural properties}

It was noticed from Figs. 4 and 5 that the flexural strength and strain of $[\mathrm{SCB}]_{8}$ are, respectively, 0.1 and 1.7 times those of $[\mathrm{G}]_{8}$. The combination of Gfiber with sugar cane bagasse reinforcement increases the flexural strength but reduces the flexural strain.

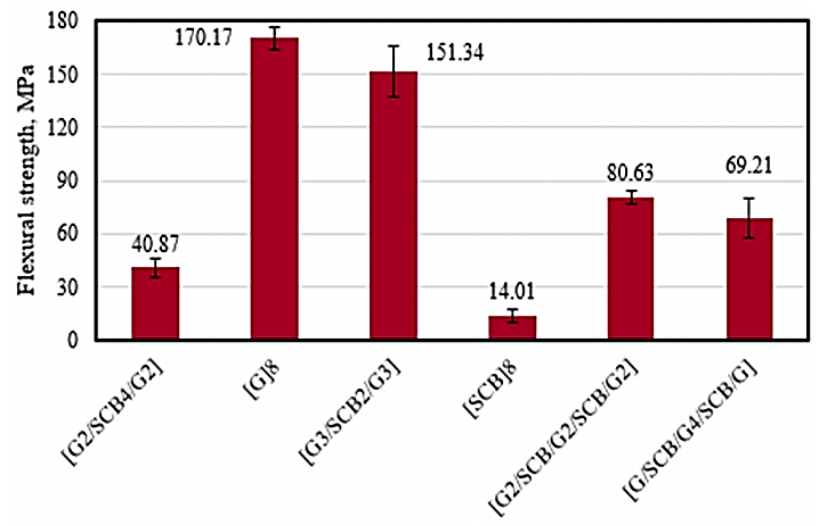

Fig. 4. Flexural strength of SCB-G reinforced composites.

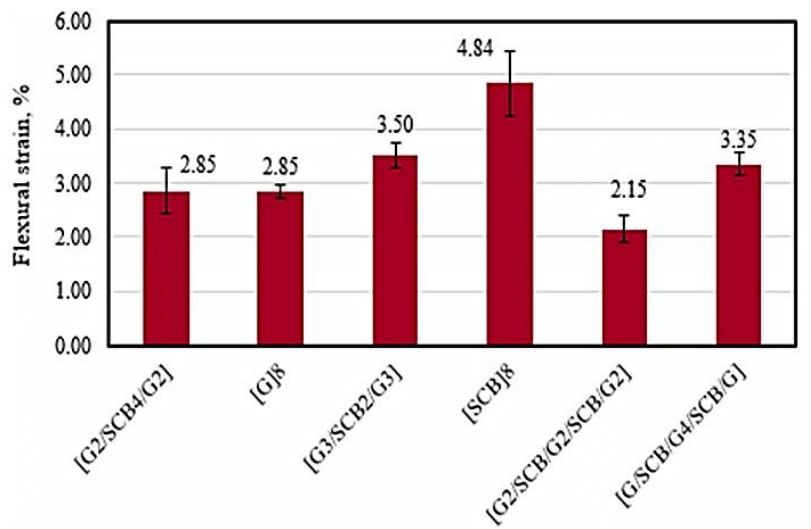

Fig. 5. Flexural strain of SCB-G reinforced composites.

The flexural performance of hybrid composites mainly relies on the reinforcement type presented on the compressive and tensile sides of the specimen. Flexural strength and strain of $\left[\mathrm{G}_{3} / \mathrm{SCB}_{2} / \mathrm{G}_{3}\right]$ are 1.88 and 1.63 times those of $\left[\mathrm{G}_{2} / \mathrm{SCB} / \mathrm{G}_{2} / \mathrm{SCB} / \mathrm{G}_{2}\right]$. Moreover, flexural strength and strain of $\left[\mathrm{G}_{3} / \mathrm{SCB}_{2} / \mathrm{G}_{3}\right]$ are about 2 and 1.14 times those of 
$\left[\mathrm{G} / \mathrm{SCB} / \mathrm{G}_{4} / \mathrm{SCB} / \mathrm{G}\right]$. This means that placing glass reinforcement at the coupon outer sides and sugar cane bagasse in the middle cause a significant enhancement in the flexural strength which is owing to flexural strength that is controlled by the outer plies. This result agrees with that obtained by $[32,33]$.

\subsection{Impact properties}

It is clear from Fig. 6 that edgewise and flatwise impact strengths of $[\mathrm{SCB}]_{8}$ are about, 0.36 and 0.29 times those of $[\mathrm{G}]_{8}$. This is due to the greater elongation of G-fiber at break compared to SCBfiber. Elongation at break and impact strength are directly correlated as reported by [34].

The addition of G-fiber to SCB increases the impact strength of hybrid composites, compared to that of $[\mathrm{SCB}]_{8}$. This result agrees with that obtained by Rahmanian et al. [35]. Hybrids have intermediate impact strengths between the parent materials. As Gfiber amount increases, impact strengths increase. The existence of G-fiber at the external layers increases impact strengths. Edgewise impact strength of $\left[\mathrm{G}_{3} / \mathrm{SCB}_{2} / \mathrm{G}_{3}\right]$ is about 1.08 and 1.17 that of $\left[\mathrm{G}_{2} / \mathrm{SCB} / \mathrm{G}_{2} / \mathrm{SCB} / \mathrm{G}_{2}\right]$ and $\left[\mathrm{G} / \mathrm{SCB} / \mathrm{G}_{4} / \mathrm{SCB} / \mathrm{G}\right]$. Flatwise impact strength of $\left[\mathrm{G}_{3} / \mathrm{SCB}_{2} / \mathrm{G}_{3}\right]$ is 1.06 and 1.10 , respectively, that of $\left[\mathrm{G}_{2} / \mathrm{SCB} / \mathrm{G}_{2} / \mathrm{SCB} / \mathrm{G}_{2}\right]$ and $\left[\mathrm{G} / \mathrm{SCB} / \mathrm{G}_{4} / \mathrm{SCB} / \mathrm{G}\right]$. This happens by the fact that the flexible layer at the impacted surface experiences larger deformation. This result agrees with that obtained by Park and Jang [36].

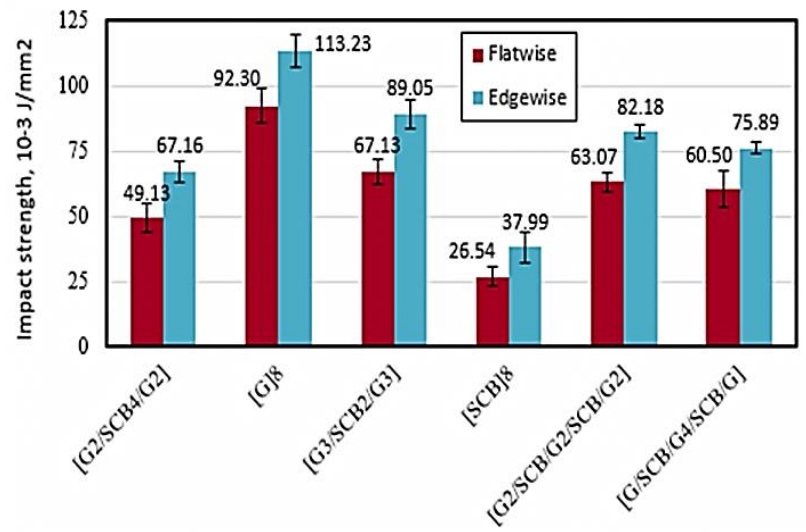

Fig. 6. Impact strengths of SCB-G reinforced composites.

\subsection{Hardness}

It is obvious from Fig. 7 that the hardness of $[\mathrm{G}]_{8}$ is about 1.79 times that of $[\mathrm{SCB}]_{8}$. As G-fiber amount at the specimen surface increases, the hardness increases. Hardness values of $\left[\mathrm{G}_{3} / \mathrm{SCB}_{2} / \mathrm{G}_{3}\right]$, $\left[\mathrm{G}_{2} / \mathrm{SCB} / \mathrm{G}_{2} / \mathrm{SCB} / \mathrm{G}_{2}\right]$ and $\left[\mathrm{G} / \mathrm{SCB} / \mathrm{G}_{4} / \mathrm{SCB} / \mathrm{G}\right]$ are, respectively, $1.11,1.03,0.98$ that of $\left[\mathrm{G}_{2} / \mathrm{SCB}_{4} / \mathrm{G}_{2}\right]$.
This is in consistent with that obtained by Megahed et al. [37].

Fig. 7. Barcol hardness of SCB-G reinforced composites.

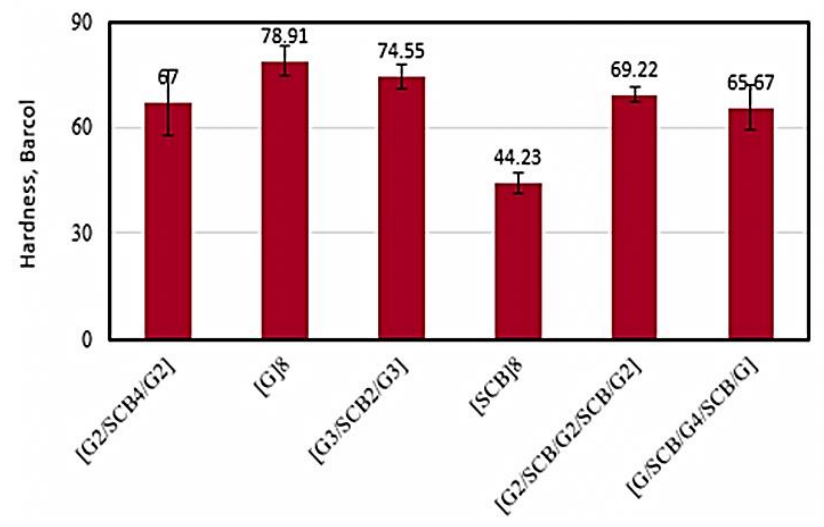

\subsection{Specific properties}

Table 4 shows the specific properties of sugar cane bagasse-G/polyester composites. It can be noticed that, $[\mathrm{G}]_{8}$ followed by $\left[\mathrm{G} / \mathrm{SCB} / \mathrm{G}_{4} / \mathrm{SCB} / \mathrm{G}\right]$ show the highest specific tensile strength. $[\mathrm{G}]_{8}$ and $\left[\mathrm{G}_{3} / \mathrm{SCB}_{2} / \mathrm{G}_{3}\right]$ exhibit the highest specific flexural strength, specific flatwise impact strength and specific edgewise impact strength. These results agree qualitatively with those obtained for rice strawglass fiber-reinforced polyester composites [35].

Table 4. Specific mechanical properties of SCB-G composites.

\begin{tabular}{|c|c|c|c|c|}
\hline Composite & $\begin{array}{c}\text { Specific } \\
\text { tensile } \\
\text { strength, } \\
\text { MPa.cm } \\
/ \mathrm{g}\end{array}$ & $\begin{array}{c}\text { Specific } \\
\text { flexural } \\
\text { strength, } \\
\text { MPa.cm } \\
/ \mathrm{g}\end{array}$ & $\begin{array}{c}\text { Specific } \\
\text { flatwise } \\
\text { impact } \\
\text { strength, } \\
\text { J.cm/g }\end{array}$ & $\begin{array}{c}\text { Specific } \\
\text { edgewise } \\
\text { impact } \\
\text { strength, } \\
\text { J.cm/g }\end{array}$ \\
\hline$\left[\mathrm{G}_{2} / \mathrm{SCB}_{4} / \mathrm{G}_{2}\right]$ & 20.48 & 37.41 & 4.51 & 6.16 \\
{$\left[\mathrm{G}_{8}\right.$} & 84.19 & 131.58 & 7.16 & 8.78 \\
{$\left[\mathrm{G}_{3} / \mathrm{SCB}_{2} / \mathrm{G}_{3}\right]$} & 37.65 & 129.59 & 5.74 & 7.61 \\
{$[\mathrm{SCB}]_{8}$} & 9.03 & 13.73 & 2.60 & 3.72 \\
{$\left[\mathrm{G}_{2} / \mathrm{SCB} / \mathrm{G}_{2} / \mathrm{SCB} / \mathrm{G}_{2}\right]$} & 42.13 & 69.97 & 5.48 & 7.15 \\
{$[\mathrm{G} / \mathrm{SCB} / \mathrm{G} 4 / \mathrm{SCB} / \mathrm{G}]$} & 45.69 & 58.97 & 5.17 & 6.49 \\
\hline
\end{tabular}

\section{6. $S E M$}

SEM for sugar cane bagasse-G/polyester composite coupons under different loadings is shown in Fig. 8. Failure signs can be summarized as polyester matrix cracking, delamination, glass fiber reinforcement breakage and sugar cane bagasse pullout.

\section{CONCLUSIONS}

The mechanical properties, tensile, flexural, impact, and hardness of SCB reinforced polyester composites have been enhanced by the incorporation of $\mathrm{G}$-fiber. $\left[\mathrm{G} / \mathrm{SCB} / \mathrm{G}_{4} / \mathrm{SCB} / \mathrm{G}\right]$ has the best tensile 
strength whilst $\left[\mathrm{G}_{3} / \mathrm{SCB}_{2} / \mathrm{G}_{3}\right]$ shows the highest flexural strength, flatwise impact strength, edgewise impact strength and hardness. Stacking sequence and relative fiber amounts have noticeable impacts on mechanical properties. The merits of the reinforcement hybridization process in this study are combining low price and light weight together with comparable mechanical properties. Consequently, the recommended hybrid composites can be utilized in moderate load applications. The suitable selection of the amounts of fibers and stacking sequence produces fabricated hybrid natural composites attaining property profiles which are close to glass fiber/polyester composites in terms of specific properties.
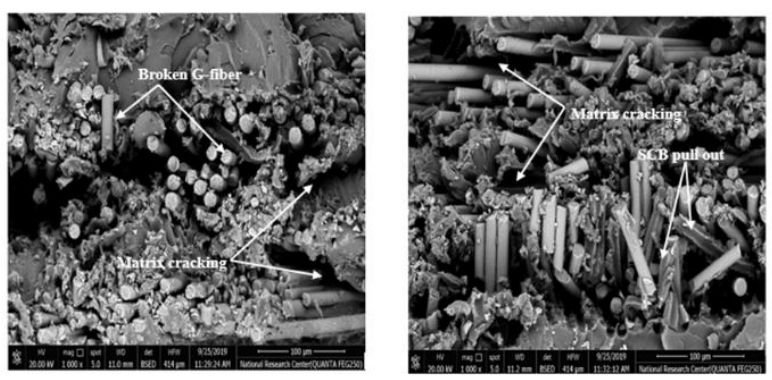

Fig. 8. SEM for failed surfaces of SCB-G reinforced composites.

\section{Acknowledgements}

The authors would thank Prof. Dr. Soliman S. Ali-Eldin, Mechanical Design and Production Eng. Department, Faculty of Eng., Zagazig University, Egypt for his support and guidance.

\section{References}

[1] P.Mishra and S. K. Acharya,. "Anisotropy abrasive wear behavior of bagasse fiber reinforced polymer composite" ,International Journal of Engineering, Science and Technology, Vol. 2,No. 11, 2010.

[2] S. V.Joshi, L. T. Drzal, A. K. Mohanty and S.Arora, ."Are natural fiber composites environmentally superior to glass fiber reinforced composites?", Composites Part A: Applied science and manufacturing, Vol. 35,No. 3,pp. 371-376, 2004.

[3] Z.S. El-Kinani, D. Sabern and A. M. Hassan,. "Characterization of wood plastic composites by using positron annihilation system", The Egyptian International Journal of Engineering Sciences and Technology, 2018.

[4] M. J.John and R. D. Anandjiwala,. "Recent developments in chemical modification and characterization of natural fiberreinforced composites", Polymer composites, Vol.29,No.2, pp.187-207, 2008.

[5] M. A. Abd El-baky,." Evaluation of mechanical properties of jute/glass/carbon fibers reinforced hybrid composites", Fibers and Polymers, Vol.18,No.12, pp.2417-32, 2017.
[6] M. M.Thwe, and K.Liao,.” Durability of bamboo-glass fiber reinforced polymer matrix hybrid composites", Composites science and technology, Vol.63,No.3 ,pp. 375-387, 2003.

[7] N.El-Tayeb,."Abrasive wear performance of untreated SCF reinforced polymer composite", Journal of Materials Processing Technology, Vol.206, NO. (1-3), PP.305-14, 2008.

[8] H. Hajiha, and M.Sain,. "The use of sugarcane bagasse fibres as reinforcements in composites", In Biofiber Reinforcements in Composite Materials Woodhead Publishing,pp. 525-549, 2015.

[9] Y. R.Loh, D.Sujan, M. E. Rahman and C. A. Das,.” Sugarcane bagasse-The future composite material: A literature review", Resources, Conservation and Recycling,Vol. 75,pp. 14-22, 2013.

[10] B.Ramaraj,." Mechanical and thermal properties of polypropylene/sugarcane bagasse composites", Journal of Applied Polymer Science, Vol.103,No. 6,pp. 3827-3832, 2007.

[11] T. E. Motaung and M. J. Mochane,." Systematic review on recent studies on sugar cane bagasse and bagasse cellulose polymer composites", Journal of Thermoplastic Composite Materials,Vol. 31,No.10,pp .1416-1432, 2018.

[12] D.Verma, P. C.Gope , M. K. Maheshwari and R. K. Sharma,. "Bagasse fiber composites-A review. J. Mater. Environ",Vol. 3,No. 6, pp.1079-1092, 2012.

[13] S. N. Monteiro, R. J. S.Rodriquez, M. V. De Souza and J. R. M. d'Almeida,. "Sugar cane bagasse waste as reinforcement in low cost composites". Advanced Performance Materials, Vol.5,No. 3, pp.183-191, 1998.

[14] M. V.Sausa de, S. N. Monteiro and J. R. M. d'Almeida, ."Evaluation of pre-treatment, size and molding pressure on flexural mechanical behavior of chopped bagasse-polyester composites". Polymer Testing, Vol.23,No. 3, pp.253-8, 2004.

[15] S.Shibata, Y. Cao, and I.Fukumoto,. "Effect of bagasse fiber on the flexural properties of biodegradable composites", Journal of Polymer Composites,Vol. 26,No. 5,pp. 689-94, 2005.

[16] Y. T.Zheng, , D. R.Cao, D. S. Wang, and J.J. Chen,. "Study on the interface modification of bagasse fibre and the mechanical properties of its composite with PVC", Composites part A: Applied Science and Manufacturing,Vol. 38 ,No.1, pp.20-5, 2007.

[17] S. K.Saw, G.Sarkhe and A.Choudhury,. "Dynamic mechanical analysis of randomly oriented short bagasse/coir hybrid fibre-reinforced epoxy novolac composites", Fibers and Polymers,Vol. 12 ,No.4,pp. 506, 2011.

[18] S. K.Saw, G.Sarkhe and A.Choudhury,. "Effect of layering pattern on the physical, mechanical, and thermal properties of jute/bagasse hybrid fiber-reinforced epoxy novolac composites", Polymer Composites, Vol.33,No.10,pp. 182431, 2012.

[19] M.Tewari, V. K.Singh, P. C.Gope, and A. K. Chaudhary,." Evaluation of mechanical properties of bagasse-glass fiber reinforced composite", J. Mater. Environ. Sci.,Vol. 3,No. 1,pp. 171-84, 2012.

[20] G. P.Otto, M. P. Moisés, G.Carvalho, A. W.Rinaldi, J. C.Garcia, E. Radovanovic and S. L Fávaro,. "Mechanical properties of a polyurethane hybrid composite with natural lignocellulosic fibers", Composites Part B: Engineering, Vol.110,pp. 459-65, 2017.

[21] M. A.Attia, M. A.Abd El-baky and A. E. Alshorbagy,. "Mechanical performance of intraply and inter-intraply hybrid composites based on e-glass and polypropylene unidirectional fibers", Journal of Composite Materials, Vol.51 ,No. 3, pp. 381-94, 2017.

[22] M. A.Abd El-baky and M.Kamel, ."Abrasive wear performance of jute-glass-carbon-reinforced composites: 
Effect of stacking sequence and fibers relative amounts",Journal of Natural Fibers,pp.1-16,2019. https://doi.org/10.1080/15440478.2019. 1616347

[23] M. A.Abd El-baky, M.Megahed, H. H.El-Saqqa and A. E Alshorbagy,." Mechanical Properties Evaluation of Sugarcane Bagasse-Glass/Polyester Composites",Journal of Natural Fibers,pp.1-18,2019. https://doi.org/10.1080/15440478.2019. 1687069

[24] T.Rajasekaran and K.Gokul,."Evaluation of mechanical characteristics of treated and untreated sugarcane fiber composites", Journal of Chemical and Pharmaceutical Sciences, Vol.9 No.1,pp. 652-6, 2016.

[25] M. A.Abd El-baky and M. A. Attia, ."Water absorption effect on the in-plane shear properties of jute-glass-carbonreinforced composites using Iosipescu test", Journal of Composite Materials, Vol. 53,No.21, pp.3033-45, 2019.

[26] ASTM D792-2013, Standard Test Methods for Density and Specific Gravity (Relative Density) of Plastics by Displacement. West Conshohocken, PA: ASTM International. WwW.astm.org

[27] ASTM D 3039-2000, Standard test method for tensile properties of polymer matrix composite materials. West Conshohocken, PA: ASTM International. www.astm.org

[28] JIS K 055-1987, Testing method for flexural properties of glass fiber reinforced plastics, Japanese Standards Association.

[29] ISO (2000) 180:2000 (E) Plastics-determination of Izod impact strength, European Standards, Int Org for Standardization: Switzerland, 3rd edn.

[30] ASTM F1957-1999, Standard Test Method for Composite Foam Hardness-Durometer Hardness, ASTM International, West Conshohocken, PA. Www.astm.org

[31] A. I.Selmy, A. R.Elsesi, , N. A.Azab and M. A. Abd El-baky, ."Monotonic properties of unidirectional glass fiber (U)/random glass fiber (R)/epoxy hybrid composites", Materials \& Design, Vol.32,No. 2,pp. 743-9, 2011.

[32] K. S. Ahmed and S.Vijayarangan,."Tensile, flexural and interlaminar shear properties of woven jute and jute-glass fabric reinforced polyester composites", Journal of Materials Processing Technology, Vol.207,No. 1-3,pp. 330-5, 2008.

[33] I. A. Subagia, Y. Kim, L. D. Tijing, and C. S. Kim,” Effect of stacking sequence on the flexural properties of hybrid composites reinforced with carbon and basalt fibers", Composites Part B: Engineering,Vol. 58,pp. 251-8, 2014.

[34] M. A. Abd El-baky," Experimental investigation on impact performance of glass-Polypropylene hybrid composites: Effect of water aging", Journal of Thermoplastic Composite Materials,Vol. 32,No.5,pp. 657-672, 2019.

[35] S.Rahmanian, K. S.Thean, A. R. Suraya, M. A. Shazed, M. M.Salleh and H. M. Yusoff,. "Carbon and glass hierarchical fibers: influence of carbon nanotubes on tensile, flexural and impact properties of short fiber reinforced composites", Materials \& Design, Vol.43, pp.10-16, 2013.

[36] R.Park and J.Jang,. "The effects of hybridization on the mechanical performance of aramid/polyethylene intraply fabric composites", Composites science and technology, Vol. 58,No.10,pp. 1621-1628, 1998.

[37] M.Megahed, S. S.Ali-Eldin, S. M. Abd El Moezz, and W. S. Abdalla,. "Synthesis of developed rice straw sheets and glass fiber-reinforced polyester composites", Journal of Composite Materials, Vol.54, No.23, pp. 3381-3394, 2020. 